\title{
Quality of life in euthymic bipolar I patients: a prospective study
}

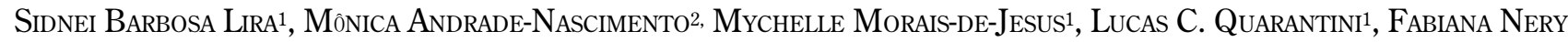 \\ Fernandes ${ }^{1}$, Diogo Esmeraldo Cavalcanti ${ }^{3}$, Amanda Galvão-de-Almeida ${ }^{1}$, Gisela Guedes 1 , Ângela Miranda-Scippa ${ }^{1}$
}

\author{
- Universidade Federal da Bahia (UFBA), Salvador, BA, Brazil. \\ 2 Universidade Estadual de Feira de Santana (UEFS), Feira de Santana, BA, Brazil. \\ 3 Universidade do Estado da Bahia (UNEB), Salvador, BA, Brazil.
}

Lira SB et al. / Arch Clin Psychiatry. 2016;43(4):92

Received: 21/6/2016 - Accepted: 12/9/2016

DOl: 10.1590/0101-60830000000091

\section{Dear Editor,}

According to the World Health Organization (WHO), Bipolar Disorder (BD) type I has a prevalence of between $1.0 \%$ and $1.6 \%$ in the general population and is one of the twenty major causes on the worldwide list of diseases that compromise an individual's total functioning ${ }^{1-3}$. Most of the quality of life (QOL) studies on BD emphasize the negative impact in the different QOL domains at all disease stages, but mainly the depressive episodes. Few studies have investigated QOL of bipolar patients during euthymia.

Thus, the present study aims to compare QOL scores in BD type I euthymic patients at two different times, with an interval of 2.5 years (only 38 from 84 could be compared due to absence of euthymia, refusal to participate, unknown location and death).

The Hamilton Rating Scale for Depression (HAM-D-17 $\leq 7)^{4}$ as well as from the Young Mania Rating Scale (YMRS $\leq 7)^{5}$ were used to evaluate if patients were euthymic. They answered a questionnaire to gather clinical and socio-demographic data. Afterwards, they were evaluated through the Structured Clinical Interview for Diagnostic and Statistical Manual of Mental Disorders, axis I (SCID-I) ${ }^{6}$. Once confirmed the BD type I diagnosis and the state of euthymia, the patient answered the World Health Organization Quality of LifeBRIEF (WHOQOL-BRIEF) instrument ${ }^{7}$.

Observations regarding the analyzed patients are as follows: female $(78.9 \%)$; average age 39.39 years (standard deviation, $\mathrm{SD}=$ $11.24)$; with no permanent partner (84.2\%); with paid occupation (60.5\%); having predominantly manic/hypomanic first episode (57.9\%); no rapid cycling (97.4\%); without suicide attempt (73.7\%); without psychiatric comorbidities (78.4\%); average age at first episode 24.5 years $(\mathrm{SD}=11.31)$, without presence of psychosis during life $(55.3 \%)$; and time of disease evolution of 14.91 years $(S D=9.9)$. In relation to the socio-demographic and clinical characteristics of the 38 subjects analyzed at both times, there were also no significant long-lasting differences $(\mathrm{p}>0.05)$.

The physical, social and psychological health domains presented reductions, but these reductions were only significant in the psychological health domain $(\mathrm{p}=0.02)($ Table 1$)$.

The psychological health domain refers to individuals' subjective experience regarding their state of psychic well-being related to their personal experience. Therefore, one assumes that $\mathrm{BD}$, by inflicting intense psychic suffering, may cause unfavorable self-analysis in these subjects, regardless of the presence of mood symptoms, resulting in the low scores found in this work. On the other hand, our results confirm the idea that bipolar patients, even when they achieve full clinical remission, show difficulties in returning to their previous level of functioning $8-10$. These findings point to the need of greater care to these individuals, even when euthymic, since unfavorable self-analysis can contribute to more social isolation behaviors, more hopelessness and greater chances of new episodes of the disease.

The main limitation of this study was the small sample size. Additionally, other limitations should be highlighted: first, the retrospective data gathered, which increased the chance of memory bias; second, the selected sample of patients from a specific medical service prevented us from generalizing the results.

Table 1. Quality of life in two different moments $(n=38)$

\begin{tabular}{|l|c|c|c|}
\hline WHO0OL domains & Baseline & Follow-up & Test $Z^{*} ; p$ value \\
\hline Physical Health & 64.28 & 60.71 & $-1.69^{* *} ; 0.091$ \\
Md (Min-Max) & $(35.71-89.29)$ & $(32.14-78.57)$ & \\
\hline Psychological Health & 66.67 & 60.42 & $-2.29^{* *} ; 0.022$ \\
Md (Min-Max) & $(33.33-100)$ & $(29.17-79.17)$ & \\
\hline Social Relations & 66.67 & 58.33 & $-0.045^{* *} ; 0.964$ \\
Md (Min-Max) & $(16.67-100)$ & $(25-100)$ & \\
\hline Environment & 51.56 & 59.37 & $-.788^{* * *} ; 0.431$ \\
Md (Min-Max) & $(31.25-90.63)$ & $(18.75-87.50)$ & \\
\hline
\end{tabular}

Md: median; Min: minimum; Max: maximum. ${ }^{*}$ Wilcoxon Test. ${ }^{* *}$ Based on positive ranks. *** Based on negative ranks.

\section{References}

1. World Health Organization (WHO). The World Health Report: Mental Health - New Understanding, New Hope; 2001.

2. Shippee ND, Shah ND, Williams MD, Moriarty JP, Frye MA, Ziegenfuss JY. Differences in demographic composition and in work, social, and functional limitations among the populations with unipolar depression and bipolar disorder: results from a nationally representative sample. Health Qual Life Outcomes. 2011;9:90.

3. Nery-Fernandes F, Miranda-Scippa A. Suicidal behavior in bipolar affective disorder and socio-demographic, clinical and neuroanatomical characteristics associated. Rev Psiquiatr Clín. 2013; 40(6):220-4.

4. Hamilton M. A rating scale for depression. J Neurol Neurosurg Psychiatry. 1960;23:56-62.

5. Young RC, Biggs JT, Ziegler VE, Meyer DA. A rating scale for mania: reliability, validity and sensitivity. Br J Psychiatry. 1978;133:429-35.

6. First MB, Spitzer RL, Gibbon M, Williams JBW. Structured Clinical Interview for the DSM-IV Axis I Disorders - Patient Edition (SCID-I/P), version 2.0. New York: Biometrics Research, New York State Psychiatric Institute; 1996.

7. Group W. WHOQOL-BRIEF: Field Trial Version. Program on Mental Health. Geneva: World Health Organization; 1996.

8. Kaya E, Aydemir O, Selcuki D. Residual symptoms in bipolar disorder: the effect of the last episode after remission. Prog Neuropsychopharmacol Biol Psychiatry. 2007;31(7):1387-92.

9. Reed C, Goetz I, Vieta E, Bassi M, Haro JM; EMBLEM Advisory Board. Work impairment in bipolar disorder patients - results from a two-year observational study (EMBLEM). Eur Psychiatry. 2010;25(6):338-44.

10. Bernstein EE, Rabideau DJ, Gigler ME, Nierenberg AA, Deckersbach T, Sylvia LG. Patient perceptions of physical health and bipolar symptoms: The intersection of mental and physical health. J Affect Disord. 2016;189:203-6. 